Original Article

\title{
Development and Evaluation of a Novel Herbal Emulgel for Potential Anti-Inflammatory and Antioxidant Activities in Vitro
}

\author{
Srilal T.L.I. ${ }^{l}$, Hettihewa S.K. ${ }^{{ }^{*}}$ \\ 1Department of Pharmacy, Faculty of Allied Health Sciences, University of Ruhuna \\ krishanthi2001@yahoo.com
}

\begin{abstract}
Emulgel is a novel topical drug delivery system which can overcome the major limitation of gel; limited delivery of hydrophobic drugs. Leea indica (Burm.f.) Merr. (Burulla) is a medicinal plant used in Sri Lankan Ayurvedic medicine for many therapeutic purposes. The present study was aimed to develop a novel herbal emulgel using Leea indica leaf extract and evaluate in vitro anti-inflammatory and antioxidant activities. Different formulations (Fg1-Fg5) were prepared by incorporating freeze dried powder of $70 \%$ aqueous acetone leaf extract. All formulations (Fg1-Fg5) were tested for their physicochemical stability parameters such as $\mathrm{pH}$, appearance, odor, homogeneity, spread ability, phase separation and washability for 60 days and they were subjected for in vitro anti-inflammatory activity by Human Red Blood Cell membrane stabilization assay and in vitro antioxidant activity by 2, 2-diphenyl-1-picrylhydrazyl (DPPH) assay respectively. Two commercially available gels were used as the positive control. Among the formulated herbal emulgels, Fg5 showed the significantly high values of in vitro anti-inflammatory and antioxidant activities compared to the tested positive controls. At the concentration of $12.5 \mathrm{mg} / \mathrm{mL}, \mathrm{Fg} 5$ showed percentage inhibition of $93.73 \pm 0.90 \%$ of heat induced hemolysis of erythrocytes and in vitro antioxidant activity of Fg5 was $3.39 \pm 0.01$ mmol Trolox per $100 \mathrm{~g}$ of emulgel. All
\end{abstract}

formulated emulgels were found to be semisolid, homogenous, and washable with water, having no phase separation and $\mathrm{pH}$ of the formulations were reported in the range of 6 to 7. There was no remarkable variation of stability parameters tested during 60 days. It is concluded that the formulated herbal emulgels have promising anti-inflammatory and antioxidant activities and formulation $\mathrm{Fg} 5$ can be recommended for further investigations using in vivo models.

Keywords: anti-inflammatory, antioxidant, emulgel, Leea indica

\section{Introduction}

Inflammation is an essential immune response which acts as a protective strategy during injury or infection in body. Body increases production of white blood cells, other immune cells and chemical mediators as a response to an inflammatory signal received by the immune system [1]. Inflammation can be either acute (a short term regulated form of inflammation) or chronic (a long-term dysregulated form of inflammation) [2] and can be harmful, if it lasts longer as a chronic inflammation or if the inflammatory response occurs in places where it is not needed [1].

Inflammatory conditions are treated mainly via orally administered Non-Steroidal AntiInflammatory Drugs (NSAIDs) which block the 
inflammatory pathways via inhibiting the mediators and factors involved in these pathways. Though these drugs are effective, they are relatively expensive and also can cause severe adverse drug reactions as well as risk of heart attack or strokes associated with NSAIDs [3].

There is a growing interest in the pharmaceutical industry for topical drug delivery systems over the other conventional routes due to its various advantages including reduced risk of systemic adverse reactions, avoidance of first pass metabolism and gastrointestinal tract variability, direct administration to desired site of action, non- invasiveness and prevention of drug-drug interactions [4]. Topical formulations of anti-inflammatory drugs are widely used in day-to-day life for pain and symptomatic relief of various acute and chronic conditions such as acute sprains, strains, overuse injuries, arthritis, neuropathic pain etc. Topical NSAID formulations are the widely prescribed group for such patients to get both analgesic and anti-inflammatory effects. Topical anti-inflammatory formulations are available in many dosage forms in the market such as gels, creams, ointments, sprays, balms and topical patches etc. [5]. Among the topical formulations, gels have been more demanded with increased patient compliance in both pharmaceutical and cosmeceutical preparations [6]. Gelling agents or gel forming polymers such as Hydroxypropyl methylcellulose (HPMC), Carbopol and Sodium carboxymethylcellulose (Sodium CMC) are essential for preparation of gels [7]. Gel formulations have many advantages over other dosage forms and the major limitation of gels is delivery of hydrophobic drugs. The new concept of topical drug delivery system known as emulgel, can successively overcome this limitation.
Emulgel is an emulsion which is gelled by mixing it with suitable gelling agent/s in accordance with the active ingredients used as Oil in Water $(\mathrm{O} / \mathrm{W})$ for lipophilic materials and Water in Oil (W/O) for hydrophilic materials [8]. It is reported as a promising drug delivery method for hydrophobic drugs. Emulgels are favorable to use as they are greaseless, easily spreadable, easily removable, non-staining, better stable, emollient and pleasing in appearance [9].

Leea indica (Burm.f.) Merr. (In Sinhala: Burulla/Gurulla) is an evergreen perennial shrub or a small tree grown in Sri Lanka. Almost all the parts of the plant including leaves, roots, fruits, stem bark and flowers are used for therapeutic purposes in certain formulations. This plant is reported to have wide range of pharmacological properties including anticancer, antioxidant, analgesic, anxiolytic potential, antiviral, thrombolytic and phosphodiesterase inhibitory activities [10], [11]. Therefore, this research aimed to develop more efficacious, cost-effective and safer antiinflammatory herbal emulgel using Leea indica (Burm.f.) Merr. Leaf extract.

\section{Materials and Methods}

\section{Plant materials and chemicals}

Leaves of Leea indica (Burm.f.) Merr. Were collected from Gampaha district (Western province, in Sri Lanka) in 2020 and were authenticated at the National Herbarium, Peradeniya, Sri Lanka. 2-2-diphenyl-1picrylhydrazyl (DPPH), trolox, carbopol-940, triethanolamine, tween 80 , tween 20, ethanol, methanol, acetone and hexane were purchased from Sigma Aldrich local agencies in Sri Lanka. 


\section{Preparation of the plant extracts}

The crude extract of $70 \%$ aqueous acetone was prepared according to a published method [12] with slight modifications. Briefly, ground powder of oven dried leaves was steeped in the solvent (300 mL) separately in Scott Duran bottles with occasional shaking (GEMMYCO shaker, Lab shaking incubator, model:IN-666) for 24 hours in the dark conditions at room temperature. After 24 hours, these extracts were filtered using four layers of muslin cloth and were concentrated under the vacuum using the rotary evaporator (HAHN HS-2005S-N) below $65{ }^{\circ} \mathrm{C}$. Partitioning with hexane was carried out to obtain the defatted crude extracts and they were then subjected to freeze drying (freeze dryer-BIOBASE BK-FD10PT) until a constant weight was gained.

\section{Formulation of herbal emulgel}

The emulgel was formulated according to the compositions given in the Table $\mathbf{1}$ by following the methods described by Singh et al. and Sultana et al. with slight modifications [13], [14].

\section{Stability testing of physicochemical parameters}

Final formulations were evaluated for their physicochemical stability parameters such as $\mathrm{pH}$, appearance, odor, homogeneity, spread ability, phase separation and washability for 60 days at room temperature.
Table 1: Composition of formulated herbal emulgels

\begin{tabular}{|c|c|c|c|c|c|c|}
\hline \multirow{2}{*}{$\begin{array}{l}\text { Ingred } \\
\text { ient }\end{array}$} & \multicolumn{6}{|c|}{ Formulations (g) } \\
\hline & Base & Fg1 & Fg2 & Fg3 & Fg4 & Fg5 \\
\hline $\begin{array}{l}\text { Freeze } \\
\text { dried } \\
\text { leaf } \\
\text { extract }\end{array}$ & - & - & 0.200 & $\begin{array}{c}0.40 \\
0\end{array}$ & $\begin{array}{c}0.20 \\
0\end{array}$ & $\begin{array}{c}0.40 \\
0\end{array}$ \\
\hline $\begin{array}{r}\text { Carbop } \\
\text { ol-940 }\end{array}$ & 0.125 & 0.125 & 0.125 & $\begin{array}{c}0.12 \\
5\end{array}$ & $\begin{array}{c}0.12 \\
5\end{array}$ & $\begin{array}{c}0.12 \\
5\end{array}$ \\
\hline $\begin{array}{l}\text { Trietha } \\
\text { nolami } \\
\text { ne }\end{array}$ & 0.100 & 0.100 & 0.100 & $\begin{array}{c}0.10 \\
0\end{array}$ & $\begin{array}{c}0.10 \\
0\end{array}$ & $\begin{array}{c}0.10 \\
0\end{array}$ \\
\hline $\begin{array}{l}\text { Castor } \\
\text { oil }\end{array}$ & 0.300 & 0.300 & 0.300 & $\begin{array}{c}0.30 \\
0\end{array}$ & $\begin{array}{c}0.30 \\
0\end{array}$ & $\begin{array}{c}0.30 \\
0\end{array}$ \\
\hline $\begin{array}{c}\text { Menth } \\
\text { ol }\end{array}$ & 1.000 & 1.000 & 1.000 & $\begin{array}{c}1.00 \\
0\end{array}$ & $\begin{array}{c}1.00 \\
0\end{array}$ & $\begin{array}{c}1.00 \\
0\end{array}$ \\
\hline $\begin{array}{l}\text { Eucaly } \\
\text { ptus oil }\end{array}$ & - & 0.400 & - & - & $\begin{array}{c}0.40 \\
0\end{array}$ & $\begin{array}{c}0.40 \\
0\end{array}$ \\
\hline $\begin{array}{l}\text { Methyl } \\
\text { salicyl } \\
\text { ate }\end{array}$ & - & 0.700 & - & - & $\begin{array}{c}0.70 \\
0\end{array}$ & $\begin{array}{c}0.70 \\
0\end{array}$ \\
\hline $\begin{array}{l}\text { Camph } \\
\text { or }\end{array}$ & - & 0.400 & - & - & $\begin{array}{c}0.40 \\
0\end{array}$ & $\begin{array}{c}0.40 \\
0\end{array}$ \\
\hline $\begin{array}{l}\text { Tween } \\
80\end{array}$ & 0.080 & 0.080 & 0.080 & $\begin{array}{c}0.08 \\
0\end{array}$ & $\begin{array}{c}0.08 \\
0\end{array}$ & $\begin{array}{c}0.08 \\
0\end{array}$ \\
\hline $\begin{array}{l}\text { Tween } \\
20\end{array}$ & 0.200 & 0.200 & 0.200 & $\begin{array}{c}0.20 \\
0\end{array}$ & $\begin{array}{c}0.20 \\
0\end{array}$ & $\begin{array}{c}0.20 \\
0\end{array}$ \\
\hline $\begin{array}{l}\text { Distille } \\
d \text { water } \\
\text { up to }\end{array}$ & Qs & Qs & Qs & Qs & Qs & Qs \\
\hline
\end{tabular}

Qs: Quantity sufficient

\section{Evaluation of in vitro anti-inflammatory activity of the formulations}

In vitro anti-inflammatory activity of formulations prepared was tested by Human Red Blood Cell (HRBC) membrane stabilization method (Heat induced Red Blood Cell hemolysis method) as described [15] with minor modifications. Briefly, the reaction 
mixture was prepared by mixing $400 \mu \mathrm{L}$ of $10 \%$ $\mathrm{RBC}$ suspension and $4.00 \mathrm{~mL}$ of emulgel sample in centrifuge tubes. The reaction mixture was incubated at $56^{\circ} \mathrm{C}$ in water bath for 30 minutes. After the incubation period, the centrifuge tubes containing reaction mixtures were centrifuged at $2500 \mathrm{rpm}$ for 5 minutes. Absorbance of the supernatants was taken at $560 \mathrm{~nm}$ using UV visible spectrophotometer (Shimatdzu UV- 1800). Commercially available two gel formulations were used as the positive controls. Negative control was prepared by adding normal saline instead of test sample. The experiment was carried out in triplicates and the percent inhibition of hemolysis was calculated by the equation given (Equation 01).

Equation 01: Calculation of percent inhibition of hemolysis [15]

Percentage inhibition of hemolysis $=(\mathrm{Vc}-\mathrm{Vt})$ $\mathrm{X} 100 / \mathrm{Vc}$

Where, $\mathrm{Vc}$ is the absorbance of the negative control and $\mathrm{Vt}$ is the absorbance of the test sample.

Evaluation of in vitro radical scavenging activity of the formulations

In vitro radical scavenging activity of the final formulations was determined using the 2, 2, diphenyl-1-picrylhydrazyl (DPPH) assay according to a published method [12]. The antioxidant activity was calculated using the standard calibration curve of Trolox and expressed as mmol Trolox equivalents to $100 \mathrm{~g}$ emulgel. Commercially available two gel formulations were used as the positive controls.

\section{Statistical analysis}

All experimental measurements were carried out in triplicates and the results were expressed as the mean \pm Standard Deviation. The results were analysed using the SPSS software version
25.0. At $(\mathrm{p}<0.05)$, the values were considered significantly different at $95 \%$ level of confidence

\section{Results}

\section{Evaluation of physicochemical stability parameters of final formulations}

All formulated herbal emulgels were found to be semi-solid, homogenous, and pleasant in odor, good in appearance with no phase separation (Fig. 1.) and $\mathrm{pH}$ of the formulations were found in the range of 6 to 7 . Physicochemical stability parameters of all formulated emulgels showed no remarkable variation during the period of 60 days tested.

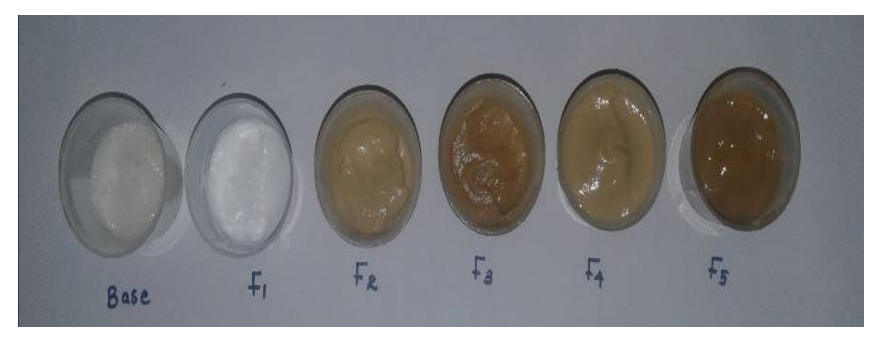

Fig. 1. Physical appearance of formulated herbal emulgels

\section{Results of in vitro anti-inflammatory activity of the final formulations}

The results of percentage inhibition of hemolysis were obtained at $12.50 \mathrm{mg} / \mathrm{mL}$ concentration of each emulgel formulation. All herbal emulgels (Fg2-Fg5) which contained $70 \%$ aq. acetone leaf extracts exhibited remarkable in vitro anti-inflammatory activity compared to the positive controls. Fg5 showed the highest percentage inhibition effect on hemolysis. 


\section{Results of in vitro antioxidant activity of the final formulations by DPPH assay}

The in vitro antioxidant activity of the formulated herbal emulgels were evaluated by using (2, 2 diphenyl-1-picrylhydrazyl) DPPH assay compared to commercial emulgels at 50 $\mathrm{mg} / \mathrm{mL}$ concentration of samples, with reference to the standard curve equation: $\mathrm{y}=$ $0.2635 \mathrm{x}, \quad \mathrm{r}^{2}=0.9966$. The results were expressed as mmol Trolox equivalents/100 $\mathrm{g}$ of formulation $\mathrm{Fg} 2, \mathrm{Fg} 3, \mathrm{Fg} 4$ and $\mathrm{Fg} 5$ herbal emulgel formulations which contained $70 \%$ acetone crude extract exhibited better antioxidant activity compared to other emulgel formulations (Table 2).

Table 2: In vitro anti-inflammatory and antioxidant activities of formulated herbal emulgels

\begin{tabular}{|c|c|c|}
\hline Formulation & $\begin{array}{l}\% \\
\text { Inhibition } \\
\pm \mathrm{SD}\end{array}$ & $\begin{array}{l}\text { Radical } \\
\text { Scavenging } \\
\text { activity } \\
\text { (mmol } \\
\text { Trolox/100 } \\
\mathrm{g} \\
\text { formulation) }\end{array}$ \\
\hline Base & $\begin{array}{ll}31.59 \quad \pm \\
0.22 & \end{array}$ & $0.048 \pm 0.00$ \\
\hline Fg1 & $\begin{array}{ll}68.16 \quad \pm \\
0.46 & \end{array}$ & $0.327 \pm 0.00$ \\
\hline $\mathrm{Fg} 2$ & $\begin{array}{ll}77.79 \quad \pm \\
0.48 & \end{array}$ & $1.779 \pm 0.01$ \\
\hline $\mathrm{Fg} 3$ & $\begin{array}{ll}81.97 \quad \pm \\
0.13\end{array}$ & $2.941 \pm 0.01$ \\
\hline $\mathrm{Fg} 4$ & $\begin{array}{ll}90.96 \quad \pm \\
0.39 & \end{array}$ & $2.934 \pm 0.01$ \\
\hline Fg5 & $\begin{array}{ll}93.73 \quad \pm \\
0.90 & \end{array}$ & $3.386 \pm 0.01$ \\
\hline Commercial gel 1 & $\begin{array}{ll}62.58 \quad \pm \\
0.64 & \end{array}$ & $0.364 \pm 0.00$ \\
\hline Commercial gel 2 & $\begin{array}{ll}58.06 \quad \pm \\
0.59\end{array}$ & $0.169 \pm 0.01$ \\
\hline
\end{tabular}

SD: Standard Deviation; mmol: mili moles

\section{Discussion}

All the formulated emulgels showed remarkable in vitro anti-inflammatory and radical scavenging antioxidant activities in the formulations developed. Formulations; $\mathrm{Fg} 2$ Fg5 which contained $70 \%$ aq. acetone leaf extracts as an ingredient exhibited significantly high values of in vitro anti-inflammatory and antioxidant activities compared to the positive controls (Commercial gels) tested. Among them, Fg5 which contained the highest concentration of plant extract (4\% of crude extract) showed the highest activities. Using ingredients such as eucalyptus oil, castor oil, methyl salicylate, camphor and menthol with known anti-inflammatory activity of the formulations developed, would have improved the efficacy of the anti-inflammatory activity. All the formulations showed no variation in the stability testing for the given period. However, further stability studies should be carried out for a considerable time period under approved conditions to confirm the stability and efficacy of the formulations which will be useful to determine its shelf life. It is recommended to evaluate a wider range of physicochemical parameters of final formulations in these stability studies. L. indica is known to possess a wide range of pharmacological activities such as antioxidant, analgesic, antimicrobial, cytotoxic, wound healing, anti-hyperglycemic, hypolipidemic, thrombolytic, sedative, anxiolytic activities etc. Srinivasan et al. revealed the presence of 23 known chemical compounds in the leaves of $L$. indica including eleven hydrocarbons, gallic acid, phthalic acid, three phthalic acid esters, palmitic acid, ursolic acid, solanesol, farnesol, 1-eicosanol, lupeol and $\beta$-sitosterol in their study using GC-MS analysis, spectroscopic analysis and co-TLC techniques [16]. Ethanolic extract of L. indica 
leaves had been tested for its phytochemical, antioxidant, antimicrobial and cytotoxic effects. Antioxidant activity was estimated by 1,1diphenyl-2-picrylhydrazyl (DPPH) assay, $\mathrm{FeCl}_{3}$ reducing power assay, alkaline DMSO method and iron chelating assay. Cytotoxic, antibacterial and antifungal activities were tested by brine shrimp bioassay, disc diffusion technique and food poison technique respectively. Phytochemical screening revealed the presence of alkaloids, glycosides, cardiac glycosides, terpenoids, flavonoids, steroids and tannins and significant values of total phenolic and flavonoid contents in the extract. Leaf extract also showed significant antioxidant, antibacterial, antifungal activities and prominent cytotoxic activity during this study [17]. Another study also had been conducted to determine the antioxidant, cytotoxic and phytochemical properties of ethanolic extract of L. indica leaves and the results had shown significant values in DPPH assay in a dose dependent manner and a promising cytotoxic activity for the brine shrimp lethality bioassay [18].

The research reported by Saha and the team stated that crude methanolic extract obtained from whole plant of $L$. indica possesses strong antioxidant and nitric oxide (NO) inhibitory activities by using scavenging activity on DPPH, Ferric thiocyanate (FTC), Thiobarbituricacid (TBA) methods and Griess assay [19]. Emran et al. evaluated the central and peripheral analgesic potential of $L$. indica plant using two experimental mice models. Ethanolic extract of $L$. indica at dose level of $200 \mathrm{mg} / \mathrm{kg}$ showed a significant reduction of writhing response for acetic acid- induced writhing test and the response were dose dependent [20]. Azizi et al. in their study investigated the wound healing effect of ethanolic extract of $L$. indica in mouse fibroblast cells and mouse macrophage cells by scratch assay and MTT (3-[4,5-dimethylthiazol2-yl]-2,5 diphenyl tetrazolium bromide) assay and the study results had proven the efficacy of L. indica in wound heling [21]. The study done by Dalu et al. had evaluated the antihyperglycemic and hypolipidemic activities of alcoholic and hydro-alcoholic extracts of $L$. indica leaves. The activities were tested with rats using glucose tolerance test and alloxan induced model compared to standard drug, glibenclamide. It was found that higher doses of hydro-alcoholic extracts more effective than alcoholic extracts in reducing blood glucose and lipid levels. Besides, acute toxicity studies performed in this research have shown that both hydro-alcoholic and alcoholic extracts are safe up to the dose level of $3000 \mathrm{mg} / \mathrm{kg}$ [22].

\section{Conclusion}

The aim of this study was to develop more efficacious, cost-effective and safer antiinflammatory herbal emulgel using $L$. indica (Burm.f.) Merr. Leaf extract. All herbal emulgels, which included $70 \%$ aqueous acetone leaf extract of $L$. indica as an ingredient, showed significantly greater in vitro antiinflammatory and antioxidant activities compared to the reference commercial formulations. Among them, Fg5 emulgel was found to be the most stable and active formulation with the highest in vitro antiinflammatory and antioxidant activities and therefore it can be recommended for further investigations in animal models.

\section{Acknowledgement}

Authors would like to express sincere gratitude to all the academic, non-academic staff members of the Department of Pharmacy, Faculty of Allied Health Sciences, University of Ruhuna, and Galle, Sri Lanka. 


\section{Conflict of Interests}

The authors declare that there is no conflict of interest.

\section{Ethical Approval}

This study was conducted after obtaining the ethical approval from the Ethics Review Committee of Faculty of Allied Health Sciences, University of Ruhuna under the reference no: 31.12.2019:2.8.

\section{Informed Consent}

For the blood withdrawal procedure in this research study, healthy human volunteers were selected among the students who were between ages 20-30 years, from the Faculty of Allied Health Sciences, University of Ruhuna, who had not taken any anti-inflammatory drug for 2 weeks prior to the blood withdrawal and the purpose and the participant's involvement were clearly explained to each and every volunteer before obtaining the consent. Written informed consent was obtained from all volunteers.

\section{References}

1)U. Ahmed, "An overview of inflammation: Mechanism and consequences", Front.Biol., vol. 6, no. 4, pp. 274-281, Aug. 2011.

2)S.N. Heendeniya, W.D. Ratnasooriya, R.N. Pathirana, "In vitro investigation of antiinflammatory activity and evaluation of phytochemical profile of Syzygium caryophyllatum", J. Pharmacogn. Phytochem., vol. 7, no. 1, pp. 1759-1763, Jan. 2018.

3) S. Kumar, B.S. Bajwa, S. Kuldeep, A. N. Kalia, "Anti-Inflammatory activity of herbal plants : A Review", Int. J. Adv. Pharm. Biol. and Chem., vol. 2, no. 2, pp. 272-281, Apr - Jun. 2013.

4) M.L. Mcpherson, N.M. Cimino, "Topical NSAID Formulations", Pain Med., vol. 14, no 1, pp. 35-39, Dec. 2013.
5) M.D. Makris, MJ. Kohler M.D., L. Fraenkel M.D., M. P. H., "Adverse effects of topical NSAIDs in older adults with osteoarthritis:a systematic review of the the literature", $\mathrm{NIH}$ Public Access,J Rheumatol., vol. 37, no.6, pp. 1236-1243, Jun. 2011,

6) A.R. Phad, N.T. Dilip, S. Ganapathy, "Emulgel: A comprehensive review for topical delivery of hydrophobic drugs", Asian J. Pharm., vol.12, no. 2, pp. 6-12, Apr-Jun. 2018

7) L.P. Kaur, T.K. Guleri, "Topical gel: A recent approach for novel drug delivery" Asian J. Biomed. Pharm. Sci., vol. 3, no. 17, pp. 1-5. Mar. 2013.

8)K. Ashara, M. Soniwala, K. Shah, "Review article emulgel: A novel drug delivery system", J. Pak. Assoc. Derma., vol. 26, no.3, pp. 244-249, Jul - Sep. 2016.

9) R. Arora, R.Khan, A. Ojha, K. Upadhyaya, H. Chopra, "Emulgel : A novel approach for hydrophobic drugs" Int. J. Pharm. Biol. Sci., vol.7, no. 3, pp. 43-60, Jul-Sep. 2017.

10) P.T.R. Kekuda, H.L. Raghavendra, N.A. Bharadwaj, S. Akhilesha, S., "Traditional uses, chemistry and pharmacological activities of Leea indica (Burm.f.) Merr. (Vitaceae): A comprehensive review", Int. J. Green Pharm., vol.12, no. 1, pp. 71-80, Jan - Mar. 2018, http://dx.doi.org/10.22377/ijgp.v12i01.1602

11) G. Mishra, P. Singh, R.L. Khosa, M.A. Tahseen, "Ethnobotany and phytopharmacology of Leea indica:An overview", J. Coast. Life Med., vol.4, no.1, pp.69-72, Jan.2016.

12) S.K. Hettihewa, "Extraction, characterization and in vitro testing of flavonoids rich fractions obtained from Actinidia macrosperma fruit", $\mathrm{PhD}$ Thesis, University of Auckland, New Zealand, 2014. 
13) V.K. Singh, P.K. Singh, P.K. Sharma, P.K. Srivastava, A. Mishra, "Formulation and evaluation of topical gel of acelofenac containing piparine", Indo Am. J. Pharm. Res,. vol.3, no. 7, pp. 5266-5280, Jul. 2013.

14) S.S. Sultana, G. Swapna, G.S.S. Lakshmi, S. Swathi, G.N. Jyothi, A.S. Devi, "Formulation and evaluation of herbal emulgel of Lantana camara leaves extract for wound healing activity in diabetic rats", Indo Am. J. Pharm. Res., vol. 6, no.8, pp. 6404-6417, Jul. 2018.

15) G. Leelaprakash, S.M. Dass, "In vitro antiinflammatory activity of methanol extract of Enicostemma axillare", Int. J. Drug Dev. Res., vol. 3, no.3, pp. 189-196, Jul-Sep. 2011.

16) G.V. Srinivasan, C. Ranjith, K.K. Vijayan, "Identification of chemical compounds from the leaves of Leea indica", Acta Pharm., vol.58, no.2, pp. 207-214, 2008.

17) Rahman, S. Islam, "Antioxidative , antimicrobial and cytotoxic effects of the phenolics of Leea indica leaf extract", Saudi J. Biol. Sci., vol.20, no.3, pp. 213-225, 2013.

18) T.B. Emran, M.A. Rahman, S.M. Hosen, U.H. Khanam, D. Saha, D, "Antioxidant, cytotoxic and phytochemical properties of the ethanol extract of Leea indica leaf', $J$. Pharm. Res., vol. 5, no.5, pp. 2938-2941, May. 2012.

19) K. Saha, N. H. Lajis, D. A. Israf, A. S. Hamzah, S. Khozirah, S. Khamis, A. Syahida, "Evaluation of antioxidant and nitric oxide inhibitory activities of selected Malaysian medicinal plants," $J$. Ethnopharmacol., vol. 92 no. 2-3, pp. 263267, Jun. 2004.

20) T.B. Emran, M.A. Rahman, S.Z. Hosen, M.M. Rahman, A.M. Islam, M.A. Chowdhury, M.E. Uddin, “Analgesic activity of Leea indica (Burm. f.) Merr.", Phytopharmacology., vol.3, no.1, pp.150-7, May. 2012.

21) W.M. Azizi, N. K. Sunzida, A.K. Azad, "The screening of local herbs in treating non healing wounds and diabetic foot ulcers complications using NIH 3T3 mouse fibroblast and Raw 264.7 mouse macrophage cells", Pharmacol Online, vol.1, pp.139-45, Apr. 2016.

22) D. Dalu, S. Duggirala, S. Akarapu, "Anti hyperglycemic and hypolipidemic activity of Leea indica”, Int. J. Bioassays., vol.3, no.7, pp.3155-3159, May. 2014. 